\title{
Induction of the multixenobiotic/multidrug resistance system in various cell lines in response to perfluorinated carboxylic acids ${ }^{\star}$
}

\author{
Izabela Rusiecka and Andrzej C. Składanowski ${ }^{凶}$ \\ Department of Molecular Enzymology, Intercollegiate Faculty of Biotechnology UG-MUG, \\ Medical University of Gdańsk, Gdańsk, Poland
}

Received: 11 March, 2008; revised: 28 April, 2008; accepted: 04 June, 2008

available on-line: 14 June, 2008

\begin{abstract}
The multixenobiotic resistance (closely related to multidrug resistance) system controls transport across the plasma membrane as a defense against toxic molecules. Multixenobiotic resistance system consists of an efflux pump, ABCB1 (also named P-glycoprotein, P-gp), and/or a molecule of the ABCC family (also named multiple resistance associated protein, MRP). ABCB1 is able to increase efflux of many low-molecular foreign molecules. Measuring system induction may be used as a biomarker of cell/organism exposure to foreign substances. Various established cell lines were tested for constitutive and induced multixenobiotic resistance proteins by Western blotting immunodetection. The pumping function was indirectly assayed with Rhodamine B by visualization of cell fluorescence in the presence of verapamil. Changes in ABC proteins were measured by flow cytometry after exposition to various perfluorinated carboxylic acids. MCF7 and HeLa cells were found to contain the highest constitutive level of both ABCB1 and ABCC1. HEK293 exhibited much less $\mathrm{ABCB} 1$ and no activity of pumping out Rhodamine $B$. The pumping activity was found to be related to the amount of the cell-type specific $170 \mathrm{kDa}$ ABCB1 protein. An 8-day exposure to $10^{-4} \mathrm{M}$ perfluorononanoic acid resulted in about 2-2.5-fold increase of ABCB1 level. That was confirmed also for short times by flow cytometry of cells exposed to perfluorinated acids and its natural congeners. Both ABCB1- and ABCC1-related fluorescence increased along with the carbon chain in acids from $C_{6}$ up to $C_{9}$ and decreased for $C_{10}$. Measuring of multixenobiotic resistance changes in vitro induced by chemicals may be a convenient test for screening for their potential toxicity.
\end{abstract}

Keywords: multixenobiotic resistance, multidrug resistance, perfluorinated carboxylic acids, flow cytometry, ABCB1, ABCC1

\section{INTRODUCTION}

The general mechanism of treatment of foreign substances by organisms involves detoxification by enzymatic modification or cleavage, alteration of accessibility to targets, decreased permeability of the cell membrane and active toxin extrusion by membrane transporters. The latter system contains an efflux pump comprising ABCB1 (also named P-glyco- protein, P-gp) and/or other proteins from the ABCC family (also named multiple resistance associated protein, MRP). The presence of the multixenobiotic resistance (MXR), analogous to the multidrug resistance (MDR) of tumor cells (Juliano \& Ling, 1976; Endicott \& Ling, 1989; Gottesman \& Pastan, 1993), was described for the first time in some aquatic organisms (Kurelec, 1992). The activity of a plasma membrane ATP-hydrolysing ABCB1-containing pump-

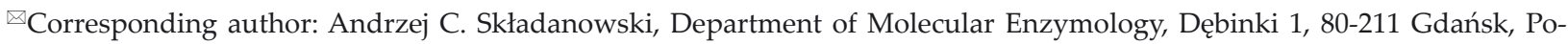
land; tel.: (48) 58349 1470; fax (48) 58349 1445; e-mail: acskla@amg.gda.pl

Preliminary report on the same subject was presented by the authors during the 41st Meeting of the Polish Biochemical Society, Białystok, 12-15 September 2006.

Abbreviations: ABC, ATP-binding cassette (generic); ABCB1, ATP-binding cassette (transporter) B1; ABCC1, ATP-binding cassette (transporter) C1; DMEM, Dulbecco modified Eagle's medium; MDR, multidrug resistance; MXR, multixenobiotic resistance; PBS, phosphate-buffered saline; PFA, perfluorinated (carboxylic) acids (general); PFHxA, PFHpA, PFOA, PFNA, PFDA (see Table 1).
} 
Table 1. Perfluorinated and natural carboxylic acids used in this study

\begin{tabular}{|c|c|c|c|c|}
\hline Common name & Molecular formula & Structural formula & MW & Abbreviation \\
\hline Perfluorohexanoic acid & $\mathrm{C}_{6} \mathrm{HF}_{11} \mathrm{O}_{2}$ & & 314 & PFHxA \\
\hline Perfluroheptanoic acid & $\mathrm{C}_{7} \mathrm{HF}_{13} \mathrm{O}_{2}$ & & 364 & PFHpA \\
\hline Perfluorooctanoic acid & $\mathrm{C}_{8} \mathrm{HF}_{15} \mathrm{O}_{2}$ & & 414 & PFOA \\
\hline Perfluorononanoic acid & $\mathrm{C}_{9} \mathrm{HF}_{17} \mathrm{O}_{2}$ & & 464 & PFNA \\
\hline Perfluorodecanoic acid & $\mathrm{C}_{10} \mathrm{HF}_{19} \mathrm{O}_{2}$ & & 514 & PFDA \\
\hline Hexanoic acid & $\mathrm{C}_{6} \mathrm{H}_{12} \mathrm{O}_{2}$ & & 116 & $\mathrm{HxA}$ \\
\hline Decanoic acid & $\mathrm{C}_{10} \mathrm{H}_{20} \mathrm{O}_{2}$ & & 172 & DA \\
\hline
\end{tabular}

ing system was confirmed by biochemical (Kurelec \& Pivčevic, 1989), molecular (Kurelec et al., 1992; Toomey \& Epel, 1993; Minier et al., 1993; Cornwall et al., 1995), physiological (Kurelec \& Pivčevic, 1991; Minier \& Moore, 1996; Galgani et al., 1996) and toxicological (Waldmann et al., 1995) methods. The wide taxonomic distribution of MXR points to its universal role in biological defense (Epel, 1998; Kurelec, 1997; Eufemia \& Epel, 2000) that rescues the owner by pumping the potentially toxic substances out of the cell. Some sensitizing agents can inhibit this system (Smital \& Kurelec, 1997).

Exposure of aquatic organisms to a polluted environment induces the expression of both MXR activity and protein titer (Kurelec et al., 1996). The activity of the transporter also correlates with the concentration of well-identified pollutants (Eufemia \& Epel, 1998). Therefore, measuring the induction of MXR in an individual or population may be used as a biomarker of exposure (Kurelec, 1997). It is suggested that measuring the MXR in vitro to evaluate the potential risk for toxicity has a low range error. The reliability of the MXR as a biomarker must be checked for various exposure conditions, and also background information on seasonal, geographical, stressor and population differences of its components must be taken into consideration (Kurelec et al., 2000).

The important feature of the MXR mechanism is its low specificity towards chemicals which can be good substrates for the transporter without being obviously toxic. Less toxic agents can compete with the more toxic ones and effectively inhibit the pumping process, thus circumventing the MXR defense system. A variety of such MXR inhibitors or competitive substrates are present in polluted waters and significantly less in non-polluted ones (Smital \& Kurelec, 1997). The competitive substrates enhance accumulation and therefore strengthen the effects of xenobiotics on aquatic organisms.

The central ABCB1 protein is encoded by a gene of the $A B C B$ gene family. The $A B C B 1$ gene seems to be functionally linked to the development of the MXR phenotype of the cell. Its product (170 $\mathrm{kDa}$ ) consists of 1280 amino acids, forming two symmetrical homologous halves in the native state, each with six putative transmembrane helices and an intracellular nucleotide binding domain (Endicott \& Ling, 1989). ABCB1 is present in some tissues, such as epithelial cells of the kidney, liver, pancreas, intestinal mucosa and in capillaries of the brain and testis. It plays there a physiological role, promoting the excretion of xenobiotics, preventing their absorption and also acting as a calcium channel. A consequence of its activity in cancer cells derived from such tissues constitutively expressing ABCB1 is an intrinsic drug resistance. In most cases, however, ABCB1-associated resistance is acquired during a contact with extracellular factors. Prolonged exposure to cytotoxic factors in vitro may lead to the selection of cells with $A B C B 1$ gene amplification. $A B C B 1$ expression de novo may also be induced by short term exposure to cytotoxic agents such as UV light (Uchiumi et al., 1993), chemotherapeutic drugs (Chaudhary \& Roninson, 1993) and inducers of the stress response (Chin et al., 1990; Vilaboa et al., 2000).

ABCC1 (another member of the multidrug resistance protein family) is a polytopic membrane transporter of considerable clinical importance that confers multidrug resistance on tumor cells by reducing drug accumulation. It is also an efficient transporter of conjugated organic anions. Like other ABC-proteins, including ABCB1, ABCC1 (190 kDa) has a core structure consisting of two membranespanning domains (MSDs), each followed by a nucleotide binding domain (NBD). Unlike ABCB1 and 
most other $\mathrm{ABC}$ superfamily members, $\mathrm{ABCC} 1$ contains a third MSD with five predicted transmembrane segments and an extracytosolic $\mathrm{NH}_{2}$-terminus. Moreover, the two NBDs in ABCC1 are considerably more divergent than those found in $\mathrm{ABCB} 1$ (Rosenberg et al., 2001).

In this study we tested five homologs of perfluorinated carboxylic acids varying in chain length (PFAs, see Table 1). They are technical substances broadly used in industry, public sector and in the household. Industrialized regions may soon envisage problems with negative effect of PFAs on living organisms (Guruge et al., 2006). PFAs are highly thermostable and environmentally persistent pollutants and the balance between lipo- and hydrophilicity makes them easily penetrable through many cellular membranes. Reproductive and developmental toxicity of the most commonly used compounds - PFOA and PFOS (perfluorooctanoic acid and perfluorooctanesulphonate) - was proved in the mouse (Lau et al., 2006). PFOS has been recently reported a danger (Brooke et al., 2004) and introduced on the list of banned substances in the European Union. We hypothesize that as anionic xenobiotics, they also can induce expression of genes encoding components of the MXR/MDR system. This study verifies this hypothesis positively.

\section{MATERIALS AND METHODS}

Cell lines and culture conditions. Cell lines: MCF7 (human breast cancer), HeLa (human cervical cancer), A375 (human melanoma) and HEK293 (human embryonic kidney) were cultivated in DMEM with $4.5 \mathrm{~g}$ glucose/L (Sigma, Germany) and WM9 (human melanoma) in RPMI-1640 (Sigma, Germany). Both media contained $10 \%$ fetal bovine serum (Gibco, USA) and 1\% PEN/STREP (Sigma, Germany). A375 and HEK293 were obtained from American Type Culture Collection and all other lines were from the local cell bank (www.biology.pl/biomobil).

Measurement of MXR activity. The procedure was performed according to Minier and Moore (1996) with small modification. Cells were incubated with $1 \mu \mathrm{M}$ Rhodamine B (Sigma, Germany, made out of $1 \mathrm{mM}$ stock) for $60 \mathrm{~min}$ with or without $20 \mu \mathrm{M}$ verapamil (Sigma, Germany, made out of $20 \mathrm{mM}$ stock) added $20 \mathrm{~min}$ after Rhodamine B. Specimens were taken, fixed in $4 \%$ formaldehyde and visualized in a fluorescence microscope (Axiovert S-200, Zeiss, Germany). Cells actively pumping out the dye emitted residual light only. ABCB1-negative cells or cells in the presence of a competitive substrate, verapamil, emitted intensive fluorescence at $551 \mathrm{~nm}$.
Localization of ABCB1 in situ. Cells were seeded at $1 \times 10^{5}$ per $22 \mathrm{~mm}$ well (12-well plate) $24 \mathrm{~h}$ prior to fixing in a dish containing $20 \mathrm{~mm}$ cover slip. The cover slips were sterilized by immersing in $75 \%$ ethanol and dried under tissue culture hood. After $24 \mathrm{~h}$ 60-80\% confluent culture was washed with PBS and treated with $400 \mu \mathrm{l}$ of $4 \%$ formaldehyde in PBS for $15 \mathrm{~min}$. Then cells were washed twice with PBS and treated with $0.1 \%$ Triton X-100 for $1 \mathrm{~min}$ and washed again with PBS. Consecutively, cells were blocked with blocking solution at room temp. for a minimum $30 \mathrm{~min}$ and immediately incubated either for $60 \mathrm{~min}$ with anti-Mdr (G1) sc-13131 antibodies $1: 100$ (Santa Cruz Biotechnology, USA) in blocking solution or for 15 min with PKH26 (Sigma, Germany) according to the instruction of the manufacturer. Cells were then washed with PBS and incubated with secondary goat anti-mouse antibodies conjugated with Alexa Fluor 488 (Molecular Probes, USA; $1: 100$ ) for $1 \mathrm{~h}$. Consecutively, cells were washed with PBS and incubated with $1 \mu \mathrm{M}$ Hoechst 33342 (Sigma, Germany), washed again with PBS and mounted on a glass plate using Vectashild mounting medium (Vector Laboratories), placed up-side down on a superfrost glass plate (Roth, Germany) and glued at the edges with a nail polish.

Western blot analysis. Western blotting was applied for the detection of the MXR components. Anti-Mdr (G1) sc-13131 monoclonal antibodies (Santa Cruz Biotechnology, USA) directed to a highly conserved epitope of human ABCB1 and monoclonal anti-human MRP1 directed to an epitope of ABCC1 were used. The MRP1 antibodies did not cross-react with other human $A B C C$ gene products. Total protein lysate $(10 \mu \mathrm{g})$ was loaded onto each lane and electrophoresis was performed in $12 \%$ or $6 \%$ polyacrylamide gel as described by Laemmli (1970). The $6 \%$ gel was used in the few cases when we focused on proteins of high molecular weight. Wide-range molecular mass protein markers 24-180 kDa (Sigma, Germany) were used as a reference. After the transfer onto a PVDF membrane and blocking with 5\% not-fat dry milk in PBS overnight at $4^{\circ} \mathrm{C}$, the blots were incubated with anti-Mdr in PBS (1:300 or 1:100) or anti-human MRP1 antibodies (Santa Cruz Biotechnology, USA; $1: 300$ ) in TBS overnight at $4^{\circ} \mathrm{C}$. Secondary antibodies conjugated to horseradish peroxidase (Santa Cruz Biotechnology, USA; $1: 3000)$ and BM Chemiluminescence Western Blotting Kit (Roche Diagnostic, Germany) were used to develop images on autoradiography film (Kodak XOmat AR, USA).

Exposure of cells to toxic substances: $\mathrm{Cd}^{2+}$ ions and PFAs. Cells were seeded in a $150 \mathrm{~mm}$ dish and cultured until about $70 \%$ confluence. Media were changed then for those containing either $10^{-6} \mathrm{M}$ $\mathrm{CdCl}_{2}$ (Sigma, Germany) or $10^{-4} \mathrm{M}$ perfluorinated 
organic acid (PFHxA, PFHpA, PFOA, PFNA, PFDA, all from Merck, USA) and incubation was continued for 3-15 days depending on the substance. The media were changed for fresh ones each 2 nd day of incubation. Thereafter cells were scraped in ice-cold PBS/protease inhibitors cocktail, lysed in $0.1 \%$ Triton X-100 in PBS, spun down at 14000 r.p.m. for $5 \mathrm{~min}$ and subjected to Western blot analysis.

Viability test. MTT [3-(4,5-dimethylthiazol2-yl)-2,5-diphenyl-2H-tetrazolium bromide] test was used to check the effect of PFAs. Cells were seeded at a density of $1 \times 10^{4}$ cells/well in a 96-well plate in $100 \mu \mathrm{l}$ of culture medium and allowed to grow $24 \mathrm{~h}$ before adding PFAs (out of $10^{-3} \mathrm{M}$ stock). Following $24 \mathrm{~h}$ incubations with various acids, $100 \mu \mathrm{l}$ of MTT solution $(5 \mathrm{mg} / \mathrm{ml}$ in PBS, $\mathrm{pH} 7.4)$ was added and incubated for the next 3-4 h. Supernatants were removed followed by the addition of $100 \mu \mathrm{l}$ of a solution containing $4 \% \mathrm{HCl}$ and $96 \%$ propan-2-ol. The $A_{570}$ of each well was determined with an automated plate reader. Survival was calculated relative to the staining value of an untreated control $(100 \%)$.

Flow cytometry. MCF7 and HeLa cells were exposed to various perfluorinated acids in three different concentrations $\left(10^{-6}, 10^{-5}, 10^{-4} \mathrm{M}\right)$. Cells were harvested by trypsinization and fixed for $10 \mathrm{~min}$ in $2 \%$ formaldehyde (Sigma, Germany). Thereafter icecold methanol (POCh, Poland; final concentration 90\%) was added for $30 \mathrm{~min}$ on ice to permeabilize cells. Antibodies against ABCB1 (anti-Mdr, sc-13131, $1: 100$ ) or ABCC1 (anti-human MRP1, 1:100) were added and samples were incubated for $1 \mathrm{~h}$ at room temperature. After washing the cells with incubation buffer (Roth, Germany; 0.5\% BSA in PBS), second-

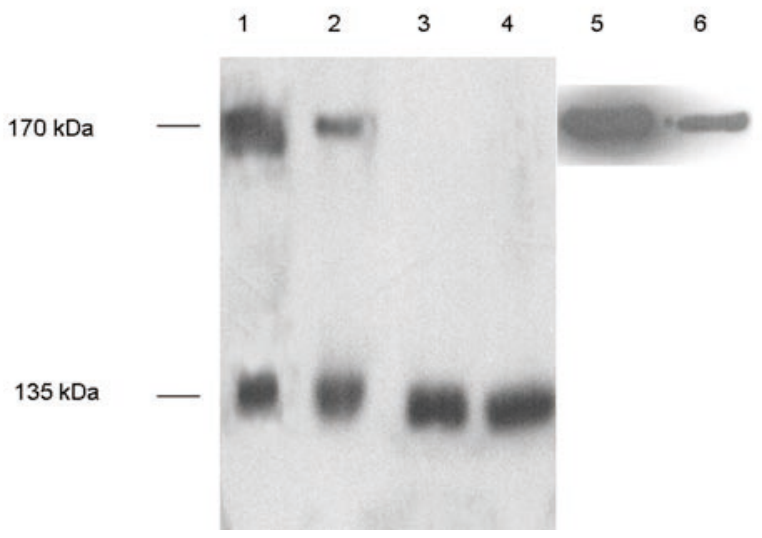

Figure 1. Presence of ABCB1 (170 kDa) in cell lysates. Lanes: 1, MCF7; 2 and 5, HeLa; 3, WM9; 4, A375; 6, HEK293). Cell extract $(10 \mu \mathrm{g})$ was electrophoresed in $12 \%$ (lanes 1-4) or 6\% (lanes 5 and 6) SDS/polyacrylamide gel, transferred onto Immobilon-P and detected with monoclonal anti-Mdr sc-13131 antibodies at $1: 300$ (lanes 1-4) or $1: 100$ (lanes 5 and 6) dilution in PBS. Standard exposition on an autoradiography film for lanes 1-4 was extended to $15 \mathrm{~min}$ for lanes 5 and 6 . Figure is a representative of minimum five experiments.

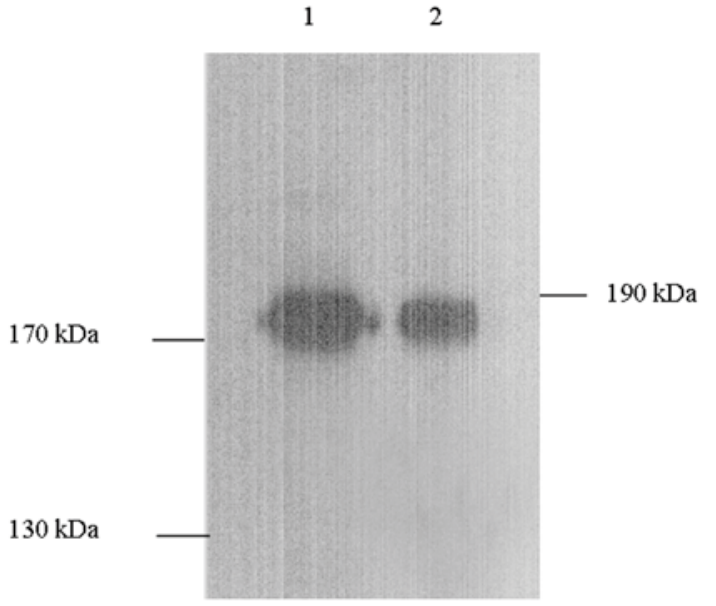

Figure 2. Presence of ABCC1 detected by anti-human MRP1 antibodies in MCF7 (lane 1) and HeLa (lane 2) cell lysates.

Cell extract $(10 \mu \mathrm{g})$ was electrophoresed in 6\% SDS/polyacrylamide gel, transferred on Immobilon-P and detected with anti-MRP1 antibodies $(1: 300)$ in TBS. Figure is a representative of minimum five experiments.

ary antibodies labeled with fluorochrome Alexa 488 (Molecular Probes, USA; $1: 400$ ) were added, followed by $1 \mathrm{~h}$ incubation in the dark and thereafter cells were washed, suspended in PBS and analyzed by flow cytometry (Beckton Dickinson LSR II).

Statistics. The data are means of three independent experiments conducted in triplicates for each acid. The percentage of fluorescence from cells was calculated from five independent experiments.

\section{RESULTS}

\section{$\mathrm{ABCB} 1$ and $\mathrm{ABCC} 1$ presence in different cell lines}

Different levels of ABCB1 components were noticed in various cells (Fig. 1). MCF7 contained the highest level of the $170 \mathrm{kDa}$ ABCB1 protein, HeLa showed a lower level, and in the melanomas WM9 and $\mathrm{A} 375$ the typical $\mathrm{ABCB} 1$ was virtually absent (Fig. 1). The non-specific second band resulted from the cross-reactivity of the anti-Mdr mAb with an unrelated protein of $135 \mathrm{kDa}$. Similar non-specific bands ranged from 135 to $170 \mathrm{kDa}$ were found earlier on immunoblots of plasma membrane preparations from multidrug-resistant mouse, hamster or human cell lines (Jette et al., 1995; Kurelec et al., 2000). HEK293 cells contained a several-fold lower level of ABCB1 than HeLa, which could be only detected in more stringent conditions - higher concentrations of antibody and longer time of film exposure (Fig. 1, lanes 5 and 6). 

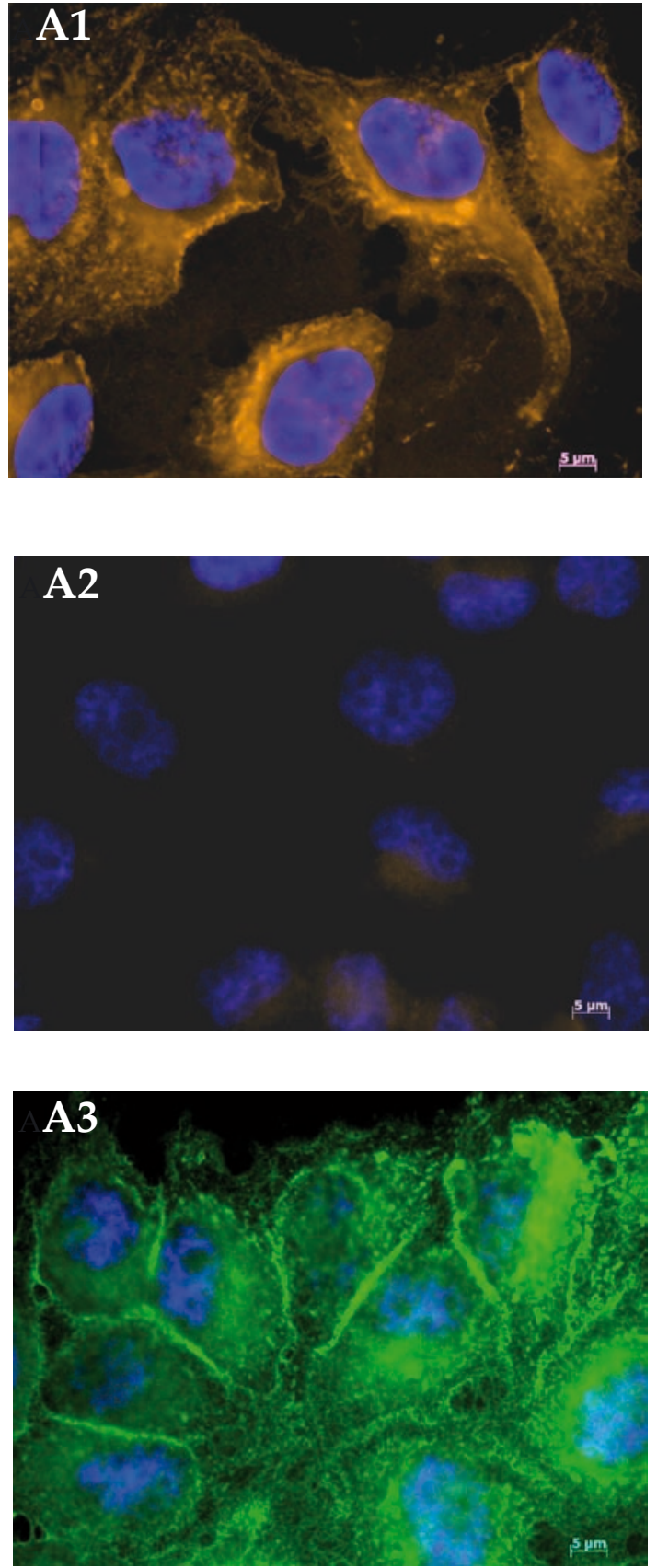

Figure 3. Activity and presence of $\mathrm{ABCB} 1$ in HeLa and HEK293 cells.

Accumulation of Rhodamine $\mathrm{B}$ inside cell in the presence of $\mathrm{ABCB} 1$ blocker - verapamil was visualized in row 1. Cells with free flow of dye (without verapamil) are presented as controls in row 2 . Specific fluorescence of cells fixed with formaldehyde and labeled with anti-Mdr antibodies conjugated with Alexa Fluor 488 is presented in row 3 Fluorescence of HEK293 cell membranes fixed with formaldehyde and labeled with PKH26 kit is presented in row 4. Nuclei were labeled with Hoechst 33342. For details of cell preparations see Materials and Methods. Figures are representatives of minimum three independent preparations.
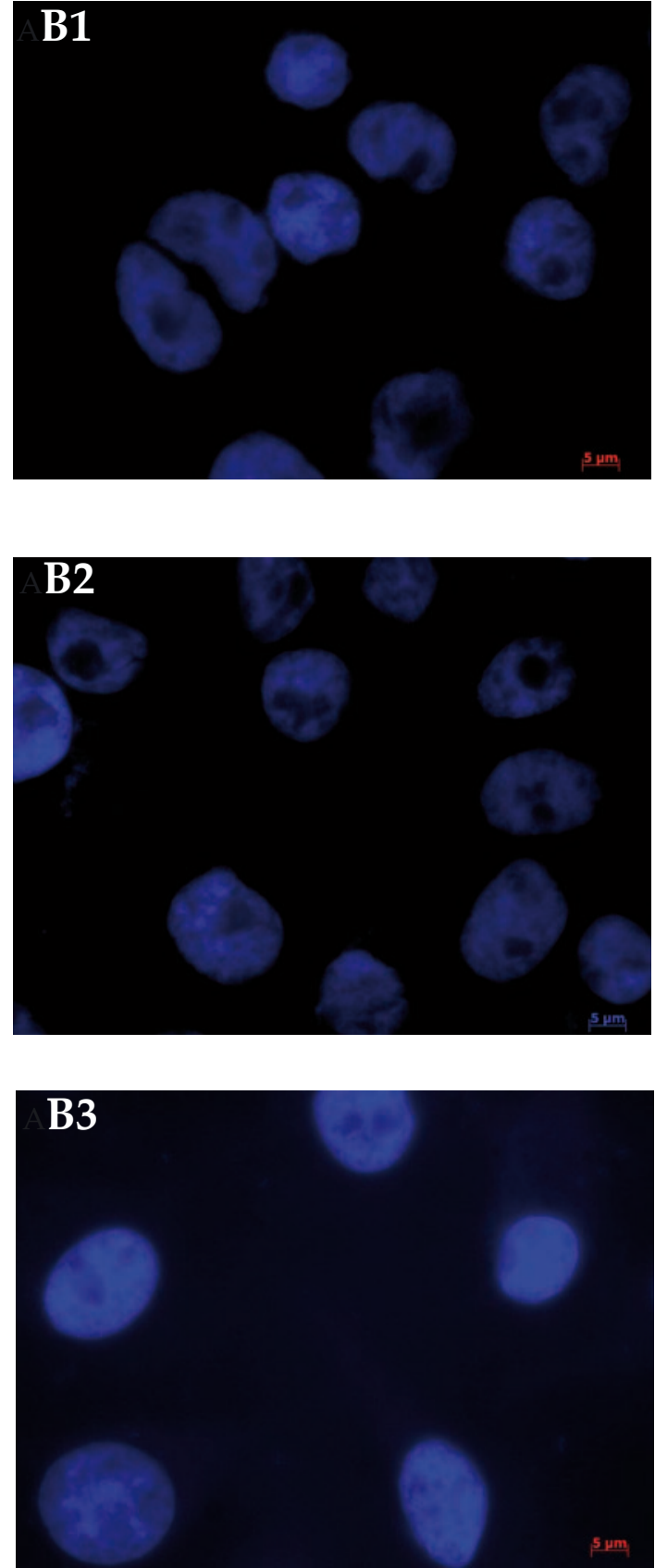

B4 
Another component of the MXR/MDR system, ABCC1, was also found in two cell lines: HeLa and MCF7. They showed a very strong signal at the level of $190 \mathrm{kDa}$ (Fig. 2).

For further investigation we chose HeLa cells, characterized by high expression of both $\mathrm{ABCB} 1$ and ABCC1.

Active pump is present in non-exposed ABCB1positive cells

The pumping function of the MXR/MDR system was verified using HeLa and HEK293 cells containing different levels of the $170 \mathrm{kDa}$ ABCB1 protein. The method of Rhodamine $B$ retention upon $A B C B 1$ active site saturation with verapamil was used earlier with single cells, such as eggs and 1-2 cell embryos from numerous marine invertebrates (Toomey \& Epel, 1993), the blood cells of a mussel (Minier \& Moore, 1996), and gill tissue of bivalves which can be treated as single-cell sheets (Cornwall et al., 1995; Kurelec et al., 2000). In our hands, the ABCB1-positive cells pumped the dye effectively out to the medium. Addition of the competitor verapamil affected the efflux so that the dye was not extruded from the cells (Fig. 3A1). In the absence of verapamil (Fig. 3A2) accumulation of the dye inside cells did not occur. HEK293 did not retain Rhodamine B regardless of the presence of verapamil (Fig. 3B1 and B2). The pumping activity of HeLa cells correlated with their high fluorescence after labeling with antiMdr antibodies conjugated with Alexa Fluor 488 (Fig. 3A3). Although the ABCB1 fluorescence did not have a single localization, it was the most intensive at the plasma membrane. ABCC1 was also found in HeLa plasma membranes (using anti-human MRP1 antibodies, not shown). At the same conditions no fluorescence was found in HEK293 cells (Fig. 3B3). Controlling the status of HEK293, we did not find substantial signs of disintegration as checked with a red fluorescent cell linker, PKH26 (Fig. 3B4).

\section{Exposure of cells to $\mathrm{Cd}^{2+}$ induces $\mathrm{ABCB} 1$ protein}

HeLa cells were tested for exposure-related changes in MXR/MDR system components through 3-15 day-long incubation with xenobiotics. Cadmium chloride, well known for its toxic properties, was a reference for further experiments. Changes of the ABCB1 band intensity are presented in Fig. 4. An about 5-fold increase of the specific $170 \mathrm{kDa} A B C B 1$ protein was detected after 8 days of incubation of the cell culture with $2.5 \mu \mathrm{M} \mathrm{Cd}^{2+}$. The well known effect (Achard et al., 2004) of $\mathrm{Cd}^{2+}$ on the expression of genes encoding

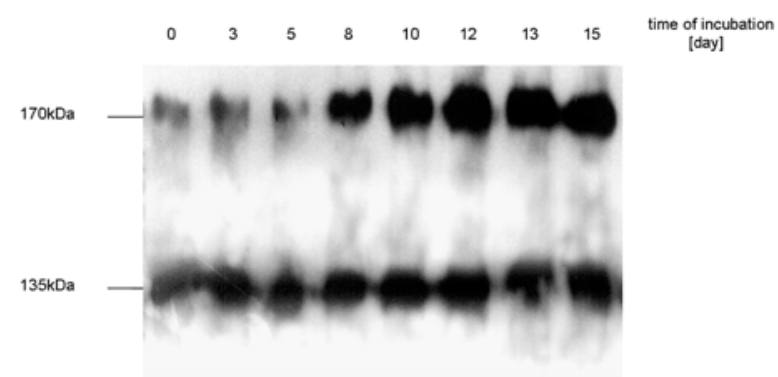

Figure 4. Changes of ABCB1 in HeLa cell lysates after 3-15 days of incubation with $10^{-6} \mathrm{M} \mathrm{CdCl}_{2}$.

Cell extract $(10 \mu \mathrm{g})$ was electrophoresed in $12 \%$ SDS/polyacrylamide gel, transferred on Immobilon-P and detected with monoclonal anti-Mdr antibodies $(1: 300)$ in PBS. Figure is representative of minimum five experiments.

the MXR system components was thus confirmed for mammalian cells.

Perfluorinated carboxylic acids are weakly toxic for HeLa cells

A weak, dose-independent cytotoxic effect was observed upon $24 \mathrm{~h}$ incubation with various perfluorinated carboxylic acids in the range $10^{-6}-10^{-4}$ M (Fig. 5). Elongation of the carbon backbone in the tested compound resulted in a decrease of cell viability. PFDA exerted the most pronounced effect. Longer incubation (up to $72 \mathrm{~h}$ ) resulted in a higher percentage of cellular death, but not exceeding $40 \%$ at $10^{-4} \mathrm{M}$ PFDA (not shown).

Exposure of cells to PFAs induces both ABCB1 and ABCC1 proteins

HeLa cells were also checked for PFA-mediated induction of genes coding for transporting proteins. We chose HeLa line as having a less pro-

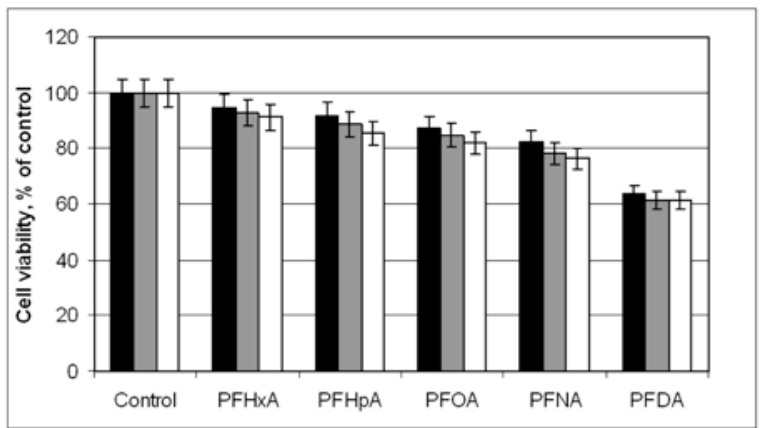

Figure 5. Viability of HeLa cells measured with MTT after $24 \mathrm{~h}$ incubation with perfluorinated acids of various chain lengths.

Concentrations were $10^{-6} \mathrm{M}$ (black), $10^{-5} \mathrm{M}$ (gray) or $10^{-4} \mathrm{M}$ (white). Bars represent S.D. $\pm 5 \%(n=3)$. 
A

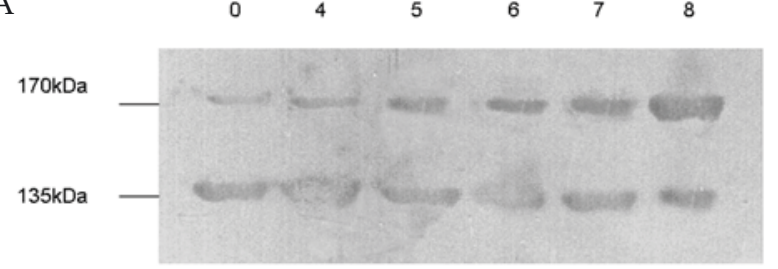

B

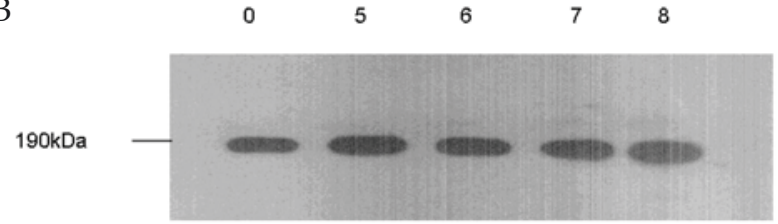

Figure 6. Changes of proteins reacting with anti-Mdr and anti-human MRP1 antibodies in HeLa lysates after 4-8 days of incubation with $10^{-4} \mathrm{M}$ PFNA.

(A) The $170 \mathrm{kDa}$ band represents $\mathrm{ABCB} 1$ and (B) the $190 \mathrm{kDa}-\mathrm{ABCC}$. The conditions were analogous as in Fig. 2 for $\mathrm{ABCC} 1$ and in Fig. 4 for $\mathrm{ABCB} 1$. Figure is representative of minimum five experiments.

nounced constitutive ABCB1 protein than MCF7 that so small changes could be easier to detect. Incubation of $\mathrm{HeLa}$ with $10^{-4} \mathrm{M}$ perfluorononanoic acid (PFNA) resulted in about 3-fold increase of the ABCB1 $170 \mathrm{kDa}$ molecular component with the nonspecific band virtually at the same level (Fig. 6A). The same experiment was performed with the use of antibodies against ABCC1 (anti-human MRP1). When HeLa cells were incubated with $10^{-4} \mathrm{M}$ PFNA for 8 days, they showed a smaller but robust 1.52-fold increase of the ABCC1 intensity (190 kDa) (Fig. 6B).

Induction of $\mathrm{ABCB} 1$ and $\mathrm{ABCC} 1$ by PFAs is carbon chain length-related

Induction of the $170 \mathrm{kDa} A B C B 1$ in the cells exposed to PFNA could be detected using immunochemistry of cell lysates (Fig. 6A). To realize our aim of finding structure-activity relationship for induction by homologous PFAs, we used a sensitive cytoimmunofluorescence method. Five different PFAs were tested by immunoflow cytometry for their influence on ABCB1 expression in HeLa cells. Normal carboxylic acids, hexanoic (HxA) and decanoic (DA), were used as controls. We observed significantly elevated ABCB1 (Fig. 7A) as

A

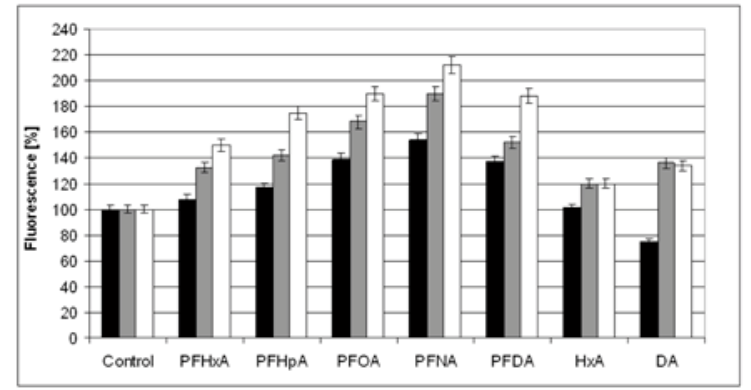

well as ABCC1 (Fig. 7B) in HeLa cells after exposure.

A significant increase in intensity of specific fluorescence coming from antibody-labeled ABCB1 was observed after 8 days of incubation with $\mathrm{C}_{6}-$ $\mathrm{C}_{10}$ perfluorinated acids. Only slight increases in the presence of its natural congeners were detected (Fig. 7A). The increase was more pronounced at higher concentrations of PFAs and a clear correlation with the chain length of the tested compounds was visible. PFHxA at $10^{-4} \mathrm{M}$ increased the level of ABCB1 on cells by $50 \%$ vs control and compounds with longer chains made this effect stronger until a maximum 2.1-fold increase was achieved with the $\mathrm{C}_{9}$-long $10^{-4} \mathrm{M}$ PFNA. Its $\mathrm{C}_{10}$ congener caused a 1.9-fold increase only. A similar correlation was observed at lower concentrations of PFAs $\left(10^{-5}\right.$ and $\left.10^{-6} \mathrm{M}\right)$.

We observed an about 50\% increase of fluorescence specific for ABCC1 on HeLa cells after incubation with $10^{-4} \mathrm{M}$ PFHxA (Fig. 7B). Longer chain PFAs elevated ABCC1 fluorescence even more significantly. The effects was better pronounced at high $10^{-4} \mathrm{M}$ concentration. Both transportation proteins, $\mathrm{ABCB} 1$ and $\mathrm{ABCC} 1$, exhibited maximum induction at the presence of $C_{9}$ long PFNA.

B

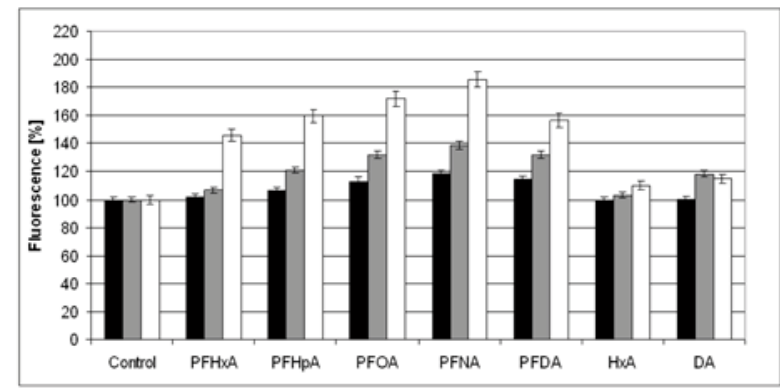

Figure 7. Effect of 8-days incubation of HeLa cells with various chain length perfluorinated or normal acids on the fluorescence of $\mathrm{ABCB} 1$ or $\mathrm{ABCC} 1$ transporters as detected by flow cytometry.

Panels represent ABCB1 (A) and ABCC1 (B). Concentrations were $10^{-6} \mathrm{M}$ (black), $10^{-5} \mathrm{M}$ (gray) or $10^{-4} \mathrm{M}$ (white). Cells incubated with specific antibodies only in the absence of effectors were used as controls. Bars represent S.D. $\pm 3 \%$ $(\mathrm{n}=15)$. 


\section{DISCUSSION}

The HeLa cell line seems to be a good model to study changes in the ABCB1 and ABCC1 proteins of the MXR/MDR system upon exposure to PFAs. These cells were relatively unsusceptible to the toxic effects of PFAs and most of them remained viable up to 15 days in culture. Another cancer cell line checked recently, colon carcinoma HCT116, exhibited $\mathrm{EC}_{50}$ of $47.7 \mu \mathrm{M}$ for PFDA (Kleszczynski et al., 2007). We checked the function of the cell membrane ion pump by Rhodamine B exclusion in combination with a specific inhibitor of calcium channel (verapamil). Retention of the dye with verapamil proved that Rhodamine can penetrate the cell. Our presumption was that the negatively charged PFAs are transported into the cell by the same mechanism as Rhodamine B and that verapamil can inhibit proteins of the $A B C$ family in HeLa cells like it did in P388 leukemia in vivo and in vitro (Tsuruo et al., 1981). Earlier we measured directly the PFDA gradient across HCT116 cell membrane in vitro (Kleszczynski et al., 2007) and proved the plausibility of cross-membrane movement of PFAs. It seems that such amphipathic compounds can accumulate in the negatively charged cell membrane despite their own charge. They could also affect efflux transporters indirectly through plasma membrane effects. Plasma membranes may directly serve as reservoirs for slowly released chemicals binding then to the active sites of the transporter proteins. Alternatively, the chemicals might have a high affinity for specific sites of the transporters such as substrate binding sites or other functional sites from where they are only slowly released, with a resulting long-term inhibition (Ferte, 2000).

Our experiments suggest that the constitutive presence of the $170 \mathrm{kDa}$ protein of the ABCB1-dependent MXR system is a prerequisite for the pumping function as indicated by comparison of HeLa and HEK293 cells. In the latter, a much lower amount of the $170 \mathrm{kDa}$ band correlated with a virtual lack of pumping activity.

We checked the in vitro influence of potentially toxic compounds on $\mathrm{ABCB} 1$ and $\mathrm{ABCC} 1$ presence. As a reference, cadmium ions, well known to induce MXR proteins (in actual nomenclature ABCB1) in exposed aquatic organisms (Achard et al., 2004), were used. A substantial increase of the ABCB1 signal after 8-day incubation of HeLa cells was observed. This confirms the existence of the same mechanism in neoplastic cell line realized through overproduction of one or more of ABC-proteins. HeLa responded also to exposure to perfluorodecanoic acid, a representative of the whole group of PFAs, although less strongly. Both $\mathrm{ABCB} 1$ and $\mathrm{ABCC} 1$ in HeLa exposed to PFDA were gradually increased with the time of incubation. It can be concluded that PFAs stimulate expression of $A B C B$ and $A B C C$ genes synchronously.

Disclosing how this stimulation is dependent on structure of PFAs will help to understand the mechanism of the effect. Changes of ABCB1 fluorescence intensity after incubation with $\mathrm{C}_{6}-\mathrm{C}_{10}$ acids for 8 days were clearly visible. They correlated with the length of the alkyl chain in the tested compounds, the longer backbone generally exerting a stronger effect. It is suggested that the recruitment of components of an active complex targeting specific genes in the nucleus is dependent on the lipophilic potential of a xenobiotic. As we found that the longest, $\mathrm{C}_{10^{-}}$ compound was a bit less stimulatory, this dependence has to be more complicated. A similar effect on ABCC1 expression suggests the same mechanism on various transport proteins whose genes can be under common control.

Testing for potential toxicity by measuring MXR/MDR protein changes in vitro can be done with relatively low error at a high diversity of inducing compounds. Data on structure-activity relationship (SAR) may help to formulate less toxic but still technologically effective chemicals for a common use. We suggest that such method after validation, may be useful and economically viable for toxicity screening.

\section{Acknowledgements}

This study was supported by grant 2 P04G 11829 from the Ministry of Science and Higher Education.

\section{REFERENCES}

Achard M, Baudrimont M, Boudou A, Bourdineaud JP (2004) Induction of a multixenobiotic resistance protein (MXR) in the Asiatic clam Corbicula fluminea after heavy metals exposure. Aquat Toxicol 67: 347-357.

Brooke D, Footitt A, Nwaogu TA (2004) Environmental Risk Evaluation Report: Perfluorooctanesulphonate (PFOS), Environment Agency, UK. http://www.environment-agency.gov.uk/commondata/105385/pfos_rer_ sept04_864557.pdf

Chaudhary PM, Roninson IB (1993) Induction of multidrug resistance in human cells by transient exposure to different chemotherapeutic drugs. J Natl Cancer Inst 85: 632-639.

Chin KV, Tanaka S, Darlington G, Pastan I, Gottesman MM (1990) Heat shock and arsenite increase expression of the multidrug resistance (MDR1) gene in human renal carcinoma cells. J Biol Chem 265: 221-226.

Cornwall R, Toomey BH, Bard S, Bacon C, Jarman WM, Epel D (1995) Characterization of multixenobiotic/ multidrug transport in the gills of the mussel Mytilus californianus and identification of environmental substrates. Aquat Toxicol 31: 277-296. 
Endicott JA, Ling V (1989) The biochemistry of P-glycoprotein-mediated multidrug resistance. Annu Rev Biochem 58: 137-171.

Epel D (1998) Use of multidrug transporters as first lines of defense against toxins in aquatic organisms. Comp Biochem Physiol A 120: 23-28.

Eufemia NA, Epel D (1998) The multixenobiotic defense mechanism in mussels is induced by substrates and non-substrates: implications for a general stress response. Mar Environ Res 46: 401-405.

Eufemia NA, Epel D (2000) Induction of the multixenobiotic defense mechanism (MXR), P-glycoprotein, in the mussel Mytilus californianus as a general cellular response to environmental stresses. Aquat Toxicol 49: 89-100.

Ferte J (2000) Analysis of the tangled relationships between P-glycoprotein-mediated multidrug resistance and the lipid phase of the cell membrane. Eur J Biochem 267: 277-294.

Galgani F, Cornwall R, Toomey BH, Epel D (1996) Interaction of environmental xenobiotics with a multixenobiotic defense mechanism in the bay mussel Mytilus galloprovincialis from the coast of California. Environ Toxicol Chem 15: 325-331.

Gottesman MM, Pastan I (1993) Biochemistry of multidrug resistance mediated by multidrug transporter. Annu Rev Biochem 62: 385-427.

Guruge KS, Yeung LW, Yamanaka N, Miyazaki S, Lam PK, Giesy JP, Jones PD, Yamashita N (2006) Gene expression profiles in rat liver treated with perfluorooctanoic acid (PFOA). Toxicol Sci 89: 93-107.

Jette L, Pouliot JF, Murphy GF, Béliveau R (1995) Isoform I (mdr3) is the major form of P-glycoprotein expressed in mouse brain capillaries. Evidence for cross-reactivity of antibody C219 with an unrelated protein. Biochem J 305: 761-766.

Juliano RL, Ling V (1976) A surface glycoprotein modulating drug permeability in Chinese hamster ovary cell mutants. Biochim Biophys Acta 455: 152-162.

Kleszczynski K, Gardzielewski P, Mulkiewicz E, Stepnowski P, Skladanowski AC (2007) Analysis of structure-cytotoxicity in vitro relationship (SAR) for perfluorinated carboxylic acids. Toxicol in Vitro 21: 1206-1211.

Kurelec B (1992) The multixenobiotic resistance mechanism in aquatic organisms. Crit Rev Toxicol 22: 23-43.

Kurelec B (1997) A new type of hazardous chemical: the chemosensitizers of multixenobiotic resistance. Environ Health Perspect 105: 855-860.

Kurelec B, Pivčevic B (1989) Distinct glutathione-dependent enzyme activities and a verapamil-sensitive binding of xenobiotics in a fresh-water mussel Anodonta cygnea. Biochem Biophys Res Commun 164: 934-940.

Kurelec B, Pivčevic B (1991) Evidence for a multixenobiotic resistance mechanism in the mussel Mytilus galloprovincalis. Aquat Toxicol 19: 291-302.

Kurelec B, KrčaS, Pivčevic B, Ugarkovic D, Bachmann M, Imsiecke G, Müller WE (1992) Expression of P-glyco- protein gene in marine sponges. Identification and characterization of the $125 \mathrm{kDa}$ drug-binding glycoprotein. Carcinogenesis 13: 69-76.

Kurelec B, Krča S, Lucic D (1996) Expression of multixenobiotic resistance mechanism in a marine mussel Mytilus galloprovincialis as a biomarker of exposure to polluted environments. Comp Biochem Physiol C 113: 283-289.

Kurelec B, Smital T, Pivčevic B, Eufemia N, Epel D (2000) Multixenobiotic resistance, P-glycoprotein and chemosensitizers. Ecotoxicol 9: 307-327.

Laemmli UK (1970) Cleavage of structural proteins during the assembly of the head of bacteriophage T4. Nature 227: 680-685.

Lau C, Thibodeaux JR, Hanson RG, Narotsky MG, Rogers JM, Lindstrom AB, Strynar MJ (2006) Effects of perfluorooctanoic acid exposure during pregnancy in the mouse. Toxicol Sci 90: 510-518.

Minier C, Akcha F, Galgani F (1993) P-glycoprotein expression in Crassostrea gigas and Mytilus edulis in polluted seawater. Comp Biochem Physiol B 106: 1029-1036.

Minier C, Moore MN (1996) Rhodamine B accumulation and MXR protein expression in mussel blood cells: Effects of exposure to vincristine. Mar Ecol Prog Ser 142: 165-173.

Rosenberg MF, Mao Q, Holzenburg A, Ford RC, Deeley RG, Cole SP (2001) The structure of the multidrug resistance protein 1 (MRP1/ABCC1). Crystallization and single-particle analysis. J Biol Chem 276: 16076-16082.

Smital T, Kurelec B (1997) Inhibitors of the multixenobiotic resistance mechanism in natural waters: in vivo demonstration of their effects. Environ Toxicol Chem 16: 2164-2170.

Toomey BH, Epel D (1993) Multixenobiotic resistance in Urechis caupo embryos: protection from environmental toxins. Biol Bull 185: 355-364.

Tsuruo T, Iida H, Tsukagoshi S, Sakurai Y (1981) Overcoming of vincristine resistance in P388 leukemia in vivo and in vitro through enhanced cytotoxicity of vincristine and vinblastine by verapamil. Cancer Res 41: 1967-1972.

Uchiumi T, Kohno K, Tanimura H, Matsuo K, Sato S, Uchida Y, Kuwano M (1993) Enhanced expression of the human multidrug resistance 1 gene in response to UV light irradiation. Cell Growth Differ 4: 147-157.

Vilaboa NE, Galan A, Troyano A, de Blas E, Aller P (2000) Regulation of multidrug resistance 1 (MDR1)/ P-glycoprotein gene expression and activity by heat-shock transcription factor 1 (HSF1). J Biol Chem 275: 2497024976.

Waldmann P, Pivčevic B, Müller WE, Zahn RK, Kurelec B (1995) Increased genotoxicity of acetylaminofluorene by modulators of multixenobiotic resistance mechanism: studies with the fresh water clam Corbicula fluminea. Mutat Res 342: 113-123. 